\title{
BIST Sektör Endekslerinin Gelişmiş Ülke Sektör Endeksleri İle İlişkisinin İncelenmesi*
}

\section{Examining the Relationship between BIST Sector Indices and Developed Country Sector Indices}

\author{
Sinem Eyüboğlu ${ }^{\text {a }}$, Kemal Eyüboğlu ${ }^{\text {b** }}$

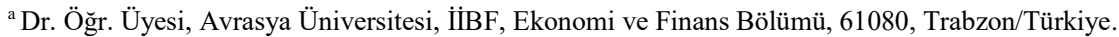 \\ ORCID: 0000-0002-3525-9173

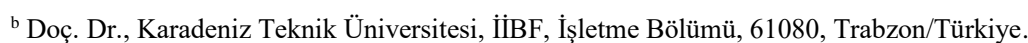 \\ ORCID: 0000-0002-2108-9732
}

\section{MAKALE BILGİSI}

\section{Makale Geçmişi:}

Başvuru tarihi: 30 Mayıs 2018

Düzeltme tarihi: 30 Ağustos 2018

Kabul tarihi: 04 Ekim 2018

\section{Anahtar Kelimeler:}

Finansal Piyasalar

Engle-Granger Eşbütünleşme Analizi

Granger Nedensellik Testi

Portföy Çeşitlendirmesi

\section{ARTICLE INFO}

\section{Article history:}

Received 30 May 2018

Received in revised form 30 August 2018

Accepted 04 October 2018

\section{Keywords:}

Financial Markets

Engle-Granger Cointegration Test

Granger Causality Test

Portfolio Diversification

\section{ÖZ}

Bilgi teknolojileri alanındaki ilerlemeler ve sermaye hareketlerinin önündeki engellerin kalkması, finansal entegrasyon sürecini hızlandırmıştır. finansal entegrasyonun artması uluslararası portföy çeşitlendirmesi açısından piyasalar arasındaki ilişkileri araştıran çalışmalara önem kazandırmıştır. Bu amaçla çalışmada 20.05.2010-03.04.2018 dönemi için günlük dolar bazlı fiyatlar kullanılarak BIST ile Dow Jones, DAX ve CAC sanayi, mali ve teknoloji sektör endeksleri arasındaki uzun dönemli ilişkinin varlığı Engle-Granger (1987) eşbütünleşme yöntemiyle analiz edilmiştir. Sonuçlar uzun dönemde 3 ülkenin sanayi endeksi ile BIST sanayi endeksinin, 3 ülkenin mali sektör endeksi ile BIST mali endeksinin ve 3 ülkenin teknoloji endeksi ile BIST teknoloji endeksinin birlikte hareket etmediklerini ortaya koymuştur. Kısa dönem dinamikleri ise Granger nedensellik testi ile incelenmiş ve BIST ile CAC sektör endekslerinin uluslararası çeşitlendirme için uygun oldukları tespit edilmiştir.

\section{A B S T R A C T}

Developments in the field of information technologies and the removal of obstacles to capital movements have accelerated the financial integration process. The increase in financial integration has given importance to studies investigating the relationship between financial markets in terms of international portfolio diversification. For this purpose, the long-term relationship between BIST and Dow Jones, DAX and CAC industry, financial and technology sector indexes is tested by EngleGranger (1987) cointegration method, taking into account daily dollar based prices for the period 20.05.2010-03.04.2018. The findings show that the industrial index of the 3 countries and the BIST Industry Index, the financial sector index of the 3 countries and the BIST Financial Index, and the technology index of the 3 countries and BIST Technology Index are not moving together in the longrun. Short-run dynamics were examined by the Granger causality test, and BIST and CAC sector indices were found to be suitable for international diversification.

\section{Giriş}

Özellikle ekonomik ve teknolojik gelișmelere paralel olarak ortaya çıkan finansal serbestleşme, uluslararası piyasalardaki sermaye hareketlerinin önündeki engelleri azaltmış ve 20 . yüzyılın sonlarına doğru finansal piyasaların entegrasyon sürecini hızlandırmıştır.

Piyasalar arasında artan entegrasyon ise riskleri çeşitlendirmiş ve risklerin daha kolay yayılabilir hale gelmelerine sebep olmuştur. $\mathrm{Bu}$ nedenle yatırımcılar için farklı ülke borsaları arasında bütünleşme olup olmadığı, uluslararası portföy çeşitlendirilmesi açısından büyük önem taşır hale gelmiştir.

Bilindiği üzere teoride bir ulusal ekonomi içerisinde iyi çeşitlendirilmiş bir portföyde bile sistematik riski ortadan kaldırmak mümkün değildir. Finansal entegrasyon ise uluslararası yatırımcılara çeşitlendirme yoluyla risklerini

* Bu çalışma, 17-20 Mayıs 2016 tarihleri arasında Saraybosna'da düzenlenen 2. Uluslararası Saraybosna Sosyal Bilimler Konferansı'nda bildiri olarak sunulmuştur.

** Sorumlu yazar/Corresponding author.

e-posta: keyuboglu@ktu.edu.tr 
minimize etme imkanı sağlamıştır. Hisse senedi piyasaları getirileri arasında zayıf korelasyon olan ülkelere ait hisse senetlerinin portföye dahil edilmesi portföy riskinin uluslararası çeşitlendirme yoluyla azaltılmasına imkan vermektedir. $\mathrm{Bu}$ açıdan finansal piyasaların birbirleriyle etkileşim düzeyinin artmasıyla birlikte hisse senedi piyasalarının bu duruma nasıl tepki verdiği üzerine yapılan çalışmalar önem kazanmıştır. Konu ile ilgili genel endeksleri (BIST-100, S\&P 500 gibi) dikkate alan çalışmalara literatürde sıklıkla rastlanırken, sektörler arası kısa ve uzun dönem ilişkiyi araştıran çalışmaların çok az sayıda olduğu görülmektedir. Carrieri vd. (2004) ekonomik entegrasyonun, endüstriyel yeniden örgütlenmenin ve ulusal sınırların kaybolmasının artmasıyla, sektör düzeyinde küresel bütünleşmenin araştırılmasının önemli olduğunu vurgulamışlardır. Aynı şekilde, Meric vd. (2005: 3377) de portföy çeşitlendirmesinde küresel sektör analizleri üzerinde yeterince durulmadığını ifade etmiştir.

$\mathrm{Bu}$ çalışmada 20.05.2010-03.04.2018 dönemi için dolar bazlı fiyatlar dikkate alınarak BIST ile Dow Jones, DAX ve CAC sektör endeksleri arasında uzun dönemli ilişki olup olmadığı araştırılmıştır. Çalışmada sektör endeksleri olarak sanayi, mali ve teknoloji endeksleri kullanılmıştır.

\section{Literatür Araştırması}

Literatürde pek çok araştırmacı, ülkeler açısından gösterge niteliği taşıyan hisse senedi piyasalarının birbirleriyle olan ilişkilerini araştırmıştır. Sektör endeksleri arasındaki ilişkileri araştıran çalışmaların ise literatürde oldukça az olduğu görülmektedir. Temel endeksleri dikkate alan çalışmalardan; Kasa (1992) 1974-1990 dönemi için ABD, Japonya, İngiltere, Almanya ve Kanada hisse senedi piyasaları arasındaki uzun dönemli ilişkiyi incelemiş ve sonuç olarak 5 piyasa arasında uzun dönemli ilişki olduğunu saptamıştır.

Ghosh vd. (1999) Mart-Aralık 1997 tarihleri arasında Hong Kong, Güney Kore, Tayvan, Malezya, Hindistan, Singapur, Tayland, Endonezya, Filipinler hisse senedi piyasalarının $A B D$ ve Japonya hisse senedi piyasaları ile uzun dönemli ilişkiye sahip olup olmadığını araştırmışlardır. Çalışma sonucunda Hong Kong, Hindistan, Kore ve Malezya hisse senedi piyasalarının ABD ile Endonezya, Singapur ve Filipinler borsalarının ise Japonya ile uzun dönemde birlikte hareket ettiği Tayvan ve Tayland piyasalarının ise hem ABD hem de Japonya ile eşbütünleşik olmadı̆̆ 1 tespit edilmiştir.

Hussain ve Saidi (2000) 1988-1993 yılları arasında Pakistan ile ABD, İngiltere, Fransa, Hong Kong, Almanya, Japonya ve Singapur hisse senedi piyasaları arasındaki ilişkiyi inceledikleri çalışmalarında Pakistan ile ABD, İngiltere ve Japonya piyasaları arasında uzun dönemli ilişki olduğunu belirlemişlerdir.

Marashdeh (2005) Türkiye, Ürdün, Fas, Misır hisse senedi piyasalarının hem kendi aralarındaki hem de bu ülke piyasalarının ABD, İngiltere ve Almanya ile uzun dönem ilişkilerini 1994-2004 dönemini ele alarak test etmişlerdir. Çalışma sonucunda elde edilen bulgular doğrultusunda, Orta Doğu ve Kuzey Afrika bölgelerindeki borsaların hem kendi aralarında hem de (Mısır hariç), ABD, İngiltere ve Almanya ile birlikte hareket etmedikleri tespit edilmiştir.
Chang vd. (2006), 1998-2001 dönemi için Tayvan hisse senedi piyasası ile Fransa, Almanya, Hollanda ve İngiltere hisse senedi piyasaları arasındaki ilişkiyi incelemişlerdir. Çalışma sonucunda Tayvan piyasasının 4 ülke hisse senedi piyasası ile eşbütünleşik olmadığı saptanmıştır.

Diamandis (2009) 1988-2006 dönemini ele alarak, ABD ile Arjantin, Brezilya, Şili ve Meksika hisse senedi piyasaları arasında eşbütünleşme ilişkisinin var olup olmadığını araştırmış ve ABD hisse senedi piyasasının 4 ülke piyasası ile uzun dönemde birlikte hareket ettiğini ifade etmiştir.

Dasgupta (2013) 1998-2012 dönemi için BRIC ile ABD hisse senedi piyasaları arasındaki ilişkileri incelemiştir. Yapılan analizler sonucunda Hindistan ve Brezilya hisse senedi piyasalarının eşbütünleşik olduğu belirlenmiştir.

Nashier (2015) 2004-2013 dönemi için BRICS ile ABD ve İngiltere hisse senetleri arasındaki uzun dönemli ilişkileri incelediği çalışmasında Brezilya- Hindistan, Güney Afrikaİngiltere, Rusya-Güney Afrika ve Rusya-İngiltere arasında eşbütünleşme ilişkisi olduğu sonucuna ulaşmıştır.

Anyikwa vd. (2018) 2003-2014 dönemi için Botswana, Misır, Gana, Fildişi, Kenya, Mauritius, Fas, Namibya, Nijerya, Güney Afrika, Tunus, Uganda ve Zambiya hisse senedi piyasaları arasındaki ilişkiyi incelemişlerdir. Çalışma sonucunda birçok hisse senedi piyasasının uzun dönemde birlikte hareket ettiği ortaya konmuştur.

Türkiye'de yapılan çalışmalarda ise Mandacı ve Taşkın (2005) 1995-2004 dönemi için İMKB ile AB üyesi ülkelerin hisse senedi piyasaları arasındaki ilişkiyi incelemişler ve IMKK'nin $\mathrm{AB}$ hisse senedi piyasaları arasındaki ilişkinin zayıf olduğunu belirlemişlerdir.

Bayri ve Güloğlu (2005) 1989-2004 dönemini 1989-2001 ve 2001-2004 olmak üzere 2 alt döneme ayırarak İMKB'nin AB ve $A B D$ hisse senedi piyasaları arasındaki uzun dönemli ilişkileri incelemişlerdir. Çalışma sonucunda ise İMKB ile $A B$ ve $A B D$ hisse senedi piyasalarının uzun dönemde birlikte hareket ettikleri ortaya konmuştur.

Küçükçolak (2008) İMKB ile İngiltere, Fransa, Almanya ve Yunanistan hisse senedi piyasaları arasındaki ilişkiyi 20012005 yılları arasını dikkate alarak incelemiş ve sonuç olarak İMKB'nin sadece Yunanistan hisse senedi piyasası ile eşbütünleşik olduğu saptanmıştır.

Akel (2015) Borsa İstanbul ile kırılgan beşli (Brezilya, Endonezya, Güney Afrika, Hindistan) olarak ifade edilen ülke borsaları arasındaki ilişkiyi 2000-2013 dönemi için ele almış ve yapılan analizler sonucunda beş ülkenin hisse senedi piyasaları arasında uzun dönemli ilişki olduğunu tespit etmişlerdir.

Sektör endekslerini dikkate alan çalışmalardan; Taing ve Worthington (2002) 1999-2002 dönemi için Belçika, Finlandiya, Fransa, Almanya, İrlanda ve İtalya borsalarında hesaplanan 5 sektör endeksi (kolayda ürünler, özelliği olan ürünler, finansal, sanayi, malzeme) arasındaki uzun dönem ilişkiyi test ettikleri çalışmalarında sektörler arasında uzun dönem ilişki olmadığını belirtmişlerdir. Ancak kısa dönemde özelliği olan ürünler ile finansal ve malzeme sektörleri arasında bir ilişki olduğunu saptamışlardır.

Çıtak ve Gözbaşı (2007) İMKB ile ABD, Almanya, İngiltere, Japonya, Hindistan ve Malezya borsaları arasındaki uzun 
dönem ilişkiyi hem temel endeks hem de sanayi, mali ve hizmetler endeksleri için 1986-2006 dönemini ele alarak araştırmışlardır. Sektör endeksleri analizine ayrıca İtalya, Fransa ve İspanya'yı da dâhil etmişlerdir. Çalışma sonucunda İMKB ile İngiltere, ABD, Almanya ve Hindistan genel endeksleri arasında uzun dönemli ilişki olduğu ortaya konmuştur. İlaveten İMKB'nin hiçbir ülke sektör endeksi ile (İtalya sanayi sektörü hariç) eşbütünleşik olmadığı tespit edilmiştir.

Hellstrand ve Korobova (2010) 2000-2009 dönemini ele alarak Brezilya, Rusya, Hindistan, ABD, İngiltere ve Japonya için petrol ve gaz sektörleri ile finansal sektör arasında herhangi bir uzun dönemli ilişki olup olmadığını araştırmışlardır. Çalışma sonucunda ise finansal sektörlerin petrol ve gaz sektörlerine oranla daha bütünleşik olduğu belirlenmiştir.

Çelik vd. (2013) ise 2010-2012 yılları arasında Brezilya ile Türkiye borsaları arasında herhangi bir ilişki olup olmadığını araştırmışlardır. Sonuç olarak XU100 ile IBOVESPA hisse senedi endeksleri arasında çift yönlü, diğer endekslerde ise sirasiyla IBrX-50 ve INDX'den XU050 ve XUSIN endekslerine doğru tek yönlü nedenselliğin olduğu ortaya konulmuştur.

Choudhry ve Osoble (2015) 2000-2009 dönemi için ABD ile Brezilya, Malezya ve Güney Afrika sanayi sektör endeksleri arasındaki ilişkileri incelemiş ve ABD ile gelişmekte olan ülke sanayi sektör endeksleri arasında nispeten zayıf bir etkileşim olduğunu, bu yüzden yatırımcıların gelişmekte olan ülke sanayi sektörlerini portföy yatırımlarını çeşitlendirmede kullanabileceklerini ifade etmişlerdir.

Shahani vd. (2017) 2006-2016 dönemi için Hindistan, ABD, Almanya ve Fransa hisse senedi sektör endeksleri arasındaki ilişkileri test etmişlerdir. Çalışma sonucunda CAC ile NYSE tüketim malları endeksleri, CAC ile hem NSE hem de NYSE ilaç endeksi arasında eşbütünleşme ilişkisi olduğu belirlenmiştir.

\section{Veri Seti ve Yöntem}

20.05.2010-03.04.2018 dönemi için Borsa İstanbul Sanayi, Mali ve Teknoloji sektör endeksleri ile Dow Jones, DAX ve CAC borsalarındaki sanayi, mali ve teknoloji sektör endeksleri arasındaki uzun dönem ilişkinin araştırıldığı bu çalışmada değişkenlere ilişkin günlük dolar bazlı fiyat seviyeleri kullanılmıştır. $\mathrm{Bu}$ endekslere ilişkin veriler ise investing.com'dan elde edilmiştir. Çalışmada serilerin doğal logaritmik halleri kullanılmıştır.

Çalışmada mali, sanayi ve teknoloji sektör endekslerinin eşbütünleşik olup olmadığı araştırılmıştır. Bu çerçevede, ilk olarak, Genişletilmiş Dickey-Fuller (ADF) ve PhillipsPerron (PP) testleri kullanılarak değişkenlerin durağanlığı test edilmiştir.

İkinci olarak, Engle-Granger (1987) eşbütünleşme yöntemi kullanılarak değişkenler arasında eşbütünleşmenin var olup olmadığ1 test edilmiştir. Engle-Granger eşbütünleşme yönteminin ilk aşamasında (1) numaralı uzun dönem denklemi en küçük kareler yöntemine göre tahmin edilerek hata terimleri elde edilmektedir.

$$
\mathrm{y}_{\mathrm{t}}=\beta_{0}+\beta_{1} \mathrm{x}_{\mathrm{t}}+\mathrm{res}_{\mathrm{t}}
$$

Denklem (1)'de y; ilgili Borsa İstanbul sektör endeksini, $x$; ilgili sektör endeksini, $\beta_{0}$; sabit terimi, $\beta_{1}$ katsayıyı, res; hata terimini ifade etmektedir. Engle-Granger eşbütünleşme yönteminin ikinci aşamasında (1) numaralı denklemden tahmin edilen hata terimlerinin durağanlığ $\breve{A D F}_{1}$ testi ile incelenir. Ardından $\boldsymbol{\varepsilon}_{\mathrm{ADF}}$ katsayısının t-istatistiği değeri Engle-Yoo (1987) tablo kritik değeriyle karşılaştırılır ve buna göre serilerin uzun dönemde birlikte hareket edip etmediklerine karar verilir.

Çalışmada serilerin arasındaki nedensellik ilişkileri ise Granger (1969) nedensellik testi incelenmiştir. Granger'in nedensellik testinde aşağıdaki denklemlerden yararlanılmıştır.

$$
\begin{aligned}
& \Delta y_{t}=\alpha_{1}+\sum_{i=1}^{p} \beta_{i} \Delta y_{t-i}+\sum_{i=1}^{k} \delta_{i} \Delta x_{t-i}+v_{t} \\
& \Delta x_{t}=\alpha_{1}+\sum_{i=1}^{m} \varphi_{i} \Delta x_{t-i}+\sum_{i=1}^{n} \lambda_{i} \Delta y_{t-i}+u_{t}
\end{aligned}
$$

Granger nedensellik testinde bağımsız değişkenin gecikmeli değerlerinin yani denklemlerde yer alan $\delta_{i}$ ve $\lambda_{i}$ 'lerin anlamlılıkları test edilir. Katsayıların anlamlı bulunması durumunda, $\mathrm{H}_{0}$ hipotezi reddedilir ve değişkenler arasında nedensellik ilişkisi olduğu kabul edilir.

\section{Bulgular}

Tablo 1'de değişkenlerin ilişkin tanımlayıcı istatistikler yer almaktadır. Buna göre en yüksek oynaklığa sahip olan sanayi endeksinin Dow Jones'a, mali endeksin DAX'a ve teknoloji endeksinin ise BIST'e ait olduğu belirlenmiştir. En düşük oynaklığa sahip olan sanayi, mali ve teknoloji endeksleri ise

\begin{tabular}{|c|c|c|c|c|c|c|}
\hline Sektör Endeksleri & 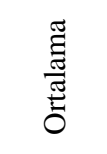 & 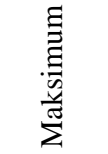 & $\begin{array}{l}\text { 声 } \\
\text { 声 }\end{array}$ & $\begin{array}{l}\tilde{E} \\
\tilde{E} \\
\tilde{E} \\
\dot{\tilde{N}} \\
\dot{\sim}\end{array}$ & $\frac{\underline{Z}}{\frac{z}{\vec{Z}}}$ & 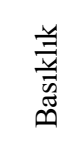 \\
\hline BIST Sanayi & & 10,556 & & & $-0,292$ & \\
\hline BIST Mali & 10,699 & 11,190 & 10,186 & 0,238 & 0,093 & 1,961 \\
\hline BIST Tekn. & 9,675 & 10,676 & 9,158 & 0,327 & 0,989 & 3,421 \\
\hline DJ Sanayi & 6,086 & 6,640 & 5,494 & 0,281 & $-0,166$ & 1,984 \\
\hline DJ Mali & 5,925 & 6,440 & 5,348 & 0,265 & $-0,126$ & 1,904 \\
\hline DJ T & & 7,540 & & 0,303 & 0,302 & 2,213 \\
\hline DAX Sanayi & 552 & 9,100 & 8,052 & 0,231 & 0,136 & 2,462 \\
\hline DAX Mali & 139 & 7,818 & 6,560 & 0,305 & 0,355 & 2,214 \\
\hline DAX & 6,580 & 7,429 & & 0,323 & 0,777 & 2,944 \\
\hline CAC Sanayi & 7,412 & 7,885 & 6,930 & 0,201 & 0,013 & 2,668 \\
\hline CAC Mali & 6,746 & 7,161 & 6,080 & 0,226 & $-0,894$ & 3,348 \\
\hline CAC Tekn. & 6,861 & 7,351 & 6,337 & 0,233 & $-0,185$ & 2,453 \\
\hline
\end{tabular}
sirasıyla BIST, CAC ve CAC endeksleridir.

Tablo 1. Tanımlayıcı İstatistikler

Engle-Granger eşbütünleşme yöntemi uygulanmadan önce serilerin durağan olup olmadıklarının test edilmesi gerekir. $\mathrm{Bu}$ amaçla Augmented Dickey-Fuller (ADF) ve PhilipsPerron (PP) birim kök testleri kullanılmış ve sonuçları Tablo 2'de sunulmuştur.

Tablo 2'ye göre tüm değişkenlerin seviyesinde birim kök içerdiği, birinci farklarında ise durağan hale geldikleri görülmektedir. 
Tablo 2. Değişkenlere Ait Birim Kök Sonuçları

\begin{tabular}{|c|c|c|c|c|}
\hline \multirow{3}{*}{ Seriler } & \multicolumn{3}{|c|}{$\mathrm{ADF}$} & \multirow{2}{*}{$\begin{array}{l}\text { PP } \\
\text { Sabitli ve } \\
\text { Trendli } \\
\end{array}$} \\
\hline & Sabitli & $\begin{array}{c}\text { Sabitli ve } \\
\text { Trendli }\end{array}$ & Sabitli & \\
\hline & \multicolumn{4}{|c|}{$\mathrm{I}(0)$} \\
\hline LBIST Sanayi & -2.48 & -2.58 & -2.50 & -2.52 \\
\hline LDJ Sanayi & -0.99 & -1.08 & -1.01 & -2.13 \\
\hline LDAX Sanayi & -1.66 & -1.76 & -1.81 & -1.87 \\
\hline LCAC Sanayi & -1.88 & -2.33 & -1.84 & -2.01 \\
\hline LBIST Mali & -1.78 & -2.56 & -1.77 & -2.25 \\
\hline LDJ Mali & -0.59 & -1.47 & -1.35 & -1.45 \\
\hline LDAX Mali & -0.89 & -2.22 & -0.99 & -2.01 \\
\hline LCAC Mali & -1.61 & -1.65 & -1.48 & -1.26 \\
\hline LBIST Tekn. & -1.75 & -1.89 & -1.87 & -1.99 \\
\hline LDJ Tekn. & -1.36 & -2.31 & -1.25 & -2.22 \\
\hline LDAX Tekn. & -2.44 & -2.49 & -2.12 & -2.15 \\
\hline \multirow[t]{2}{*}{ LCAC Tekn. } & -1.66 & -1.69 & -1.57 & -1.66 \\
\hline & \multicolumn{4}{|c|}{ I (1) } \\
\hline $\begin{array}{c}\text { DLBIST } \\
\text { Sanayi }\end{array}$ & $-19.8^{a}$ & $-19.8^{a}$ & $-24.4^{\mathrm{a}}$ & $-24.5^{\mathrm{a}}$ \\
\hline DLDJ Sanayi & $-41.2^{\mathrm{a}}$ & $-41.2^{\mathrm{a}}$ & $-41.1^{\mathrm{a}}$ & $-41.9^{\mathrm{a}}$ \\
\hline $\begin{array}{c}\text { DLDAX } \\
\text { Sanayi }\end{array}$ & $-39.4^{a}$ & $-39.7^{a}$ & $-41.0^{\mathrm{a}}$ & $-41.6^{a}$ \\
\hline $\begin{array}{c}\text { DLCAC } \\
\text { Sanayi }\end{array}$ & $-33.8^{a}$ & $-35.8^{a}$ & $-37.0^{\mathrm{a}}$ & $-37.2^{\mathrm{a}}$ \\
\hline DLBIST Mali & $-39.5^{\mathrm{a}}$ & $-39.5^{\mathrm{a}}$ & $-40.1^{a}$ & $-41.8^{a}$ \\
\hline DLDJ Mali & $-36.2^{\mathrm{a}}$ & $-37.3^{\mathrm{a}}$ & $-40.1^{\mathrm{a}}$ & $-40.2^{\mathrm{a}}$ \\
\hline DLDAX Mali & $-40.4^{a}$ & $-40.3^{\mathrm{a}}$ & $-40.1^{a}$ & $-40.2^{\mathrm{a}}$ \\
\hline DLCAC Mali & $-41.5^{\mathrm{a}}$ & $-41.7^{\mathrm{a}}$ & $-42.2^{\mathrm{a}}$ & $-44.4^{\mathrm{a}}$ \\
\hline DLBIST Tekn. & $-40.1^{\mathrm{a}}$ & $-41.6^{a}$ & $-40.2^{\mathrm{a}}$ & $-40.2^{\mathrm{a}}$ \\
\hline DLDJ Tekn. & $-39.9^{a}$ & $-39.9^{\mathrm{a}}$ & $-39.9^{a}$ & $-39.5^{\mathrm{a}}$ \\
\hline DLDAX Tekn. & $-39.6^{a}$ & $-39.2^{\mathrm{a}}$ & $-39.6^{\mathrm{a}}$ & $-39.4^{\mathrm{a}}$ \\
\hline DLCAC Tekn. & $-38.8^{a}$ & $-39 .^{a}$ & $-39.2^{\mathrm{a}}$ & $-39.9^{a}$ \\
\hline
\end{tabular}

Aynı seviyeden durağan olduğu belirlenen Borsa İstanbul sektör endeksleri ile diğer 3 ülkenin sektör endeksleri arasındaki uzun dönem ilişskinin tahmin edildiği EngleGranger eşbütünleşme testi sonuçları Tablo 3'te yer almaktadır. Test sonuçları 3 ülkenin sanayi endeksi ile BIST sanayi endeksi, 3 ülkenin mali sektör endeksi ile BIST mali endeksi ve 3 ülkenin teknoloji endeksi ile BIST teknoloji endeksi arasında uzun dönemli ilişki olmadığını ortaya koymuştur.

Tablo 3. Engle-Granger Eşbütünleşme Testi Sonuçları*

\begin{tabular}{lc}
\hline Uzun Dönem İlişki & $\varepsilon_{\mathrm{ADF}}$ \\
\hline BIST Sanayi-Dow Jones Sanayi & $-2.863406(2)$ \\
BIST Sanayi-DAX Sanayi & $-2.811408(2)$ \\
BIST Sanayi-CAC Sanayi & $-2.853213(2)$ \\
BIST Mali- Dow Jones Mali & $-2.829631(0)$ \\
BIST Mali-DAX Mali & $-2.737174(0)$ \\
BIST Mali-CAC Mali & $-2.089697(0)$ \\
BIST Tekn.-Dow Jones Tekn. & $-2.480788(2)$ \\
BIST Teknoloji-DAX Teknoloji & $-2.961477(0)$ \\
BIST Teknoloji-CAC Teknoloji & $-1.977948(0)$ \\
\hline
\end{tabular}

* Engle-Yoo (1987) tablo kritik değerleri \%1 için -4.00, \%5 için 3.37 ve \%10 için -3.03 'tür. Parantez içindeki değerler optimal gecikme uzunluklarıdır. Optimal gecikme uzunluğunun belirlenmesinde Schwarz bilgi kriterinden yararlanılmıştır ve maksimum gecikme uzunluğu 25 olarak alınmıştır.
Kısa dönem dinamikleri ise Granger nedensellik testi ile incelenmiştir. Tablo 4'e göre, sanayi endeksleri açısından Borsa İstanbul ile Dow Jones, Dax ve CAC sanayi endeksleri arasında herhangi bir nedensellik ilişkisinin varlığına dair bir bulguya ulaşılamamıştır.

Mali endeksler dikkate alındığında ise Dow Jones ve DAX mali sektör endekslerinin ayrı ayrı BIST Mali endeksinin nedeni olduğu belirlenmiştir. Teknoloji endeksleri açısından elde edilen sonuçlar ise mali endeks sonuçlarına benzer bir şekildedir. Buna göre Dow Jones Teknoloji ve Dax Teknoloji endekslerinden BIST Teknoloji endeksine doğru tek yönlü bir nedensellik olduğu tespit edilmiştir.

Tablo 4. Granger Nedensellik Testi Sonuçları

\begin{tabular}{|c|c|}
\hline Nedenselliğin Yönü & WALD Testi \\
\hline BIST Sanayi $\rightarrow \quad$ DJ Sanayi & 1.68027 \\
\hline DJ Sanayi $\rightarrow$ & 0.45537 \\
\hline BIST Sanayi $\rightarrow$ DAX Sanayi & 0.76440 \\
\hline DAX $\rightarrow \quad$ Sanayi BIST Sanayi & 1.60368 \\
\hline BIST Sanayi $\rightarrow$ CAC Sanayi & 2.24913 \\
\hline CAC Sanayi $\rightarrow \quad$ BIST Sanayi & 1.19218 \\
\hline BIST Mali $\rightarrow$ DJ Mali & 1.28208 \\
\hline DJ Mali $\rightarrow \quad$ BIST Mali & $3.47210^{\mathrm{b}}$ \\
\hline BIST Mali $\rightarrow$ DAX Mali & 0.49187 \\
\hline DAX Mali $\rightarrow$ BIST Mali & $3.52995^{\mathrm{b}}$ \\
\hline BIST Mali $\rightarrow$ CAC Mali & 0.19996 \\
\hline CAC Mali $\rightarrow \quad$ BIST Mali & 0.12603 \\
\hline BIST Teknoloji $\rightarrow$ DJ Teknoloji & 1.51414 \\
\hline DJ Teknoloji $\rightarrow \quad$ BIST Teknoloji & $2.41366^{\mathrm{c}}$ \\
\hline BIST Teknoloji $\rightarrow \quad$ DAX Teknoloji & 0.67302 \\
\hline DAX Teknoloji $\rightarrow$ & $7.02694^{\mathrm{a}}$ \\
\hline BIST Teknoloji $\rightarrow \quad$ CAC Teknoloji & 1.18505 \\
\hline CAC Teknoloji $\rightarrow$ BIST Teknoloji & 0.78719 \\
\hline
\end{tabular}

\section{Sonuç ve Öneriler}

Literatürde sıkça araştırılan konuların başında uluslararası portföy çeşitlendirmesi gelmektedir. Ancak bu çalışmalarda genellikle genel endeksler dikkate alınmaktadır. $\mathrm{Bu}$ çalışmada 20.05.2010-03.04.2018 dönemi için portföy çeşitlendirmesi BIST ile Dow Jones, DAX ve CAC sanayi, mali ve teknoloji sektör endeksleri arasında uzun dönem ilişki olup olmadiğı açısından ele alınmıştır.

Birinci farklarında durağan oldukları tespit edilen seriler arasındaki uzun dönemli ilişkilerin var olup olmadığının incelenmesinde Engle-Granger (1987) eşbütünleşme yöntemi kullanılmıştır. Yapılan analiz sonucunda 3 ülkenin sanayi endeksi ile BIST sanayi endeksi, 3 ülkenin mali sektör endeksi ile BIST mali endeksi ve 3 ülkenin teknoloji endeksi ile BIST teknoloji endeksi arasında uzun dönem ilişki olmadığı tespit edilmiştir. Bu sonuçlar literatürde yer alan Ghosh vd. (1999); Marashdeh (2005); Chang vd. (2006); Taing ve Worthington (2002); Çıtak ve Gözbaş1 (2007); Choudhry ve Osoble (2015) çalışma bulguları ile örtüşmektedir. Sonuçlara göre uzun dönemde Borsa İstanbul Sanayi, Mali ve Teknoloji sektör endekslerinin uluslararası çeşitlendirme açısından önemli firsatlar sunduğu söylenebilir.

Kısa dönem dinamikleri ise Granger nedensellik testi ile incelenmiştir. Elde edilen sonuçlara göre sanayi endeksleri için BIST ile üç gelişmiş ülke borsa endeksi arasında nedensellik olmadığı belirlenmiştir. Mali ve Teknoloji 
endeksleri için ise Dow Jones ve DAX Mali ve Teknoloji endekslerinin BIST Mali ve Teknoloji endeksinin Granger nedeni olduğu tespit edilmiştir. Bu bulgulardan yola çıkarak kısa dönemde mali ve teknoloji sektörleri açısından BIST ile CAC borsalarının uluslararası çeșitlendirme için uygun olduklarını söylemek mümkündür. Aynı şekilde, sanayi endeksleri açısından BIST Sanayi endeksi, üç gelişmiş ülke sanayi endeksine yatırım yapan uluslararası yatırımcılar açısından riski yaymak için kullanılabilir.

İlerleyen çalışmalarda farklı ülkeler veya farklı endeksler dikkate alınarak literatüre katkı sağlanabilir.

\section{Kaynakça}

Akel, V. (2015). Kırılgan beşli ülkelerinin hisse senedi piyasaları arasındaki eşbütünleşme analizi. Uluslararası Yönetim İktisat ve Işsletme Dergisi, 11 (24), 75-96.

Anyikwa, I., Brookes, M., \& Le Roux, P. (2018). African stock markets integration: An analysis of the relationship between major stock markets in Africa (No. 1812).

Bayri, O., \& Güloğlu, B. (2005). Hisse senedi ve yabancı para piyasalarının entegrasyonu: Türkiye, $\mathrm{AB}$ ve $\mathrm{ABD}$ örneği. İktisat, Işletme ve Finans Dergisi, 13-34.

Carrieri, F., Errunza, V., \& Sarkissian, S. (2004). Industry risk and market integration. Management Science, 5(50), 207-221.

Çelik, İ., Kaya, M., \& Tunç, H. (2013). Uluslararası portföy çeşitlendirmesi açısından gelişmekte olan ülke borsaları arasındaki eşhareketlilik: Brezilya-Türkiye üzerine bir uygulama. Süleyman Demirel Üniversitesi İktisadi ve İdari Bilimler Fakültesi Dergisi, 18(1), 167-180.

Chang, T., Nieh, C.C., \& Wei, C.C. (2006). Analysis of longrun benefits from international equity diversification between Taiwan and its major European trading partners: An empirical note. Applied Economics, 38, 2227-2283.

Choudhry, T., \& Osoble, B. N. (2015). Nonlinear interdependence between the US and emerging markets' industrial stock sectors. International Journal of Finance \& Economics, 20 (1), 61-79.

Çıtak, L., \& Gözbaşı, O. (2007). İMKB ile bazı önde gelen gelişmiş ve gelişmekte olan ülke borsaları arasındaki bütünleşmenin temel endeks ve ana sektör endeksleri temelinde analizi. Dokuz Eylül Üniversitesi İktisadi ve Idari Bilimler Fakültesi Dergisi, 22 (2), 249-271.

Dasgupta, R. (2013). BRIC and US Integration and dynamic linkages an empirical study for international diversification strategy. Interdisciplinary Journal of Contemporary Research in Business, 5(7), 536-563.

Diamandis, P.F. (2009). International stock market linkages: Evidence from Latin Amerika. Global Finance Journal, 20 (1), 13-30.

Dickey, D.A., \& Fuller, W.A. (1981). Likelihood Ratio Statistics for Autoregressive Time Series with a Unit Root. Econometrica, 49 (4), 1057-1072.

Engle, R. F., \& Granger W. J. (1987). Cointegration and error correction: Representation, estimation, and testing. Econometrica, 55, 251-276.
Engle, R. F., \& Yoo, B. S. (1987). Forecasting and Testing in co-integrated Systems. Journal of Econometrics, 35, 143-159.

Ghosh, A, Saidi, R., \& Johnson, K.H. (1999). Who moves the Asia-Pacific stock market-US or Japan? Empirical evidence based on the theory of cointegration. The Financial Review, 34, 159-170.

Hellstrand, A., \& Korobova, E. (2010). Cointegration and Causality in International Stock Markets. Thesis in Finance. Stockholm: Stockholm School of Economics.

Hussain, F., \& Saidi, R. (2000). The integration of the Pakistan equity market with international equity markets: An investigation. Journal of International Development, $12,207-218$

Investing (2018). Dünya ve Sektör Endeksleri. (Erişim Tarihi: 05.04.2018), https://tr.investing.com/indices/world-indices

Kasa, K. (1992). Common stochastic trends in international stock markets. Journal of Monetary Economics, 29, 95124.

Küçükçolak, N. (2008). Cointegration of the Turkish equity market with Greek and other European Union equity markets. International Research Journal of Finance and Economics, 13, 58-73.

Mandacı, P. E., \& Taşkın, D. (2005). AB'ye uyum sürecinde IMKB'nin AB piyasaları ile karşılaştırılması. Muhasebe Finansman Dergisi, 26, 127-137.

Marashdeh, H. (2005). Stock market integration in the MENA Region: An application of ARDL Bounds Testing approach. University of Wollongong, Economic Working Paper Series. (Erişim Tarihi: 05.04.2018), www.uow.edu.au/commerce/econ /wpapers.html.

Meric, I., Ratner, M., \& Meric, G. (2005). Co-movements of the world's sector index returns. International Journal of Finance, 17, 3376-3391.

Nashier, T. (2015). Financial integration between BRICS and developed stock markets. International Journal of Business and Management Invention, 4 (1), 65-7.

Phillips, P. C., \& Perron, P. (1988). Testing for a unit root in time series regression. Biometrika, 75 (2), 335-346.

Shahani, R., Talwar, A., \& Gupta, S. (2017). Dynamics of the co-movement of the returns of the sectorial stock indices of India, US and European Economies. IUP Journal of Financial Risk Management, 14 (3), 7-21.

Taing, S. H., \& Worthington, A. C. (2002). Comovements among European Equity Sectors: Selected Evidence from the Consumer Discretionary, Consumer Staples, Financial, Industrial And Materials Sectors. School of Economics and Finance Discussion Papers and Working Papers Series 116, School of Economics and Finance, Queensland University of Technology. 